\title{
Reflexões baseadas no diálogo entre o exame nacional do ensino médio, currículo e prática docente no ensino de química
}

\section{RESUMO}

Letícia Teles Carvalho telescarvalho.leticia07@gmail.com 0000-0002-8028-4976 Instituto Federal de Educação, Ciências e Tecnologia de São Paulo, São Paulo, São Paulo, Brasil.

Elisa de Silvério Ciszevski elisaosc@gmail.com 0000-0001-5783-1727

Escola Estadual Dr. Alberto Cardoso de Mello Neto, São Paulo,

São Paulo, Brasil.

Elaine Pavini Cintra elainecintra@ifsp.edu.br 0000-0003-4340-856X Instituto Federal de Educação, Ciências e Tecnologia de São Paulo, São Paulo, São Paulo, Brasil.

\begin{abstract}
O estudo aqui apresentado propõe um diálogo entre três esferas importantes dentro da educação básica: o currículo, a prática docente e as avaliações externas, em especial o Enem. Os conteúdos conceituais investigados foram selecionados a partir da análise das provas azuis do Enem de 2009 a 2015 e do Currículo Estadual Paulista. Estes conteúdos foram utilizados na construção de um questionário de perguntas em escala Likert, respondido por um grupo de docentes de química atuantes em escolas públicas estaduais. Cada conteúdo foi analisado pelos docentes tendo em vista quatro critérios: ocorrência em sala, prioridade para o docente, dificuldade e receptividade para os alunos. Os resultados demonstram que há congruência para os conteúdos orientados para 10 ano do ensino médio, caracterizado por conhecimentos da química geral. Para o 20 e 3 o anos do ensino médio a observou-se divergência entre conteúdos avaliados nas provas e aqueles presentes no currículo real, desenvolvidos pelos docentes analisados.
\end{abstract}

PALAVRAS-CHAVE: Enem. Currículo. Prática docente. Ensino de química. 


\section{INTRODUÇÃO}

Um aspecto importante de uma avaliação em larga escala é a verificação da congruência entre os instrumentos de medida utilizados, o currículo e o conteúdo de instrução (SHEPARD; PENUEL; DAVIDSON, 2017). As matrizes de referência, embora sejam elaboradas entorno de um currículo, fazem um recorte privilegiando alguns conceitos em detrimento de outros (DE BLASIS, 2013), semelhante ao que ocorre no planejamento de aula dos docentes (SACRISTÁN, 2000). Segundo Martone e Sireci (2009), a verificação da consonância do conteúdo, no que diz respeito à demanda cognitiva e ocorrência, nas provas e no currículo é um aspecto importante do processo avaliativo.

Neste trabalho é apresentada uma reflexão sobre a consonância entre os conteúdos conceituais de química presentes no Currículo do Estado de São Paulo, no Exame Nacional do Ensino Médio (Enem) e a prática de um grupo de docentes de escolas públicas estaduais da cidade de São Paulo.

\section{O Exame Nacional do Ensino Médio}

O Exame Nacional do Ensino Médio (Enem) é um exame desenvolvido pelo Instituto Nacional de Estudos e Pesquisas Educacionais Anísio Teixeira (INEP). Ele vem sendo proposto desde 1998 aos alunos egressos do ensino médio (EM), ou que já o concluíram em anos anteriores (FACHINETTO, 2016), com o intuito avaliar o desempenho escolar ao fim deste nível acadêmico. De acordo com o Edital $n^{\circ} 13$ de $07 / 04 / 2017$, seus resultados devem possibilitar a auto avaliação do participante, a criação de uma possível referência nacional para o aperfeiçoamento dos currículos do Ensino Médio, o acesso à educação superior e a programas governamentais de financiamento ao estudante e o desenvolvimento de estudos e indicadores sobre a educação brasileira (BRASIL, 2017).

Embora o Enem não seja censitário ou por amostragem é um exame que possui grande adesão no Brasil. É norteado por uma Matriz de Referência (INEP, 2009) pautada em 5 eixos cognitivos comuns a todas as áreas, a saber: dominar linguagens, compreender fenômenos, enfrentar situações-problema, construir argumentação e elaborar propostas. Essa Matriz compila habilidades e competências desenvolvidas no período de escolarização que devem ser contempladas na elaboração dos itens utilizados na composição do exame. As provas do Enem são compostas por 180 itens de múltipla escolha, 45 em cada uma das áreas do saber: Linguagens, Códigos e suas Tecnologias; Matemática e suas Tecnologias, Ciências Humanas e suas Tecnologias, Ciências da Natureza e suas Tecnologias. Além disso, a Matriz traz um anexo que apresenta uma listagem de conteúdos organizados para cada área do conhecimento (INEP, 2009). A disciplina de química dispõe de uma listagem extensa de conteúdos segmentados em 10 temas gerais (ex.: transformações químicas, compostos de carbono etc). Autores como Maceno et al. (2011) e Marcelino e Recena (2012) criticam essa listagem tradicional e volumosa de conteúdos na Matriz de Referência do Enem para a área da química, pois pode servir como reforço a programas de ensino tradicionais, mantendo práticas pedagógicas que se distanciam de um ensino com conhecimentos de caráter mais aplicado. 


\section{A prática docente e o Currículo}

Embora as avaliações e os exames possam ser considerados reflexos da concepção de ensino vigente, esse só pode ser concretizado pela prática docente. Segundo De Blasis (2013, p. 261), "[...] a ação pedagógica transcorre com a finalidade de estimular nos estudantes o desenvolvimento de diversas capacidades, por meio do contato com diferentes conteúdos e conhecimentos previamente selecionados". Na seleção desses conhecimentos cabe ao docente o decisivo papel da "[...] concretização dos conteúdos e significados dos currículos, moldando-os a partir de sua cultura profissional [...]" (SACRISTÁN, 2000, p. 105), atuando como tradutor de significados.

Sacristán (2000) discute que o currículo não se configura somente como um documento oficial de orientação, nomeado de currículo oficial, mas é um híbrido de currículos, incluindo o currículo manifesto e o currículo oculto que, integrados, resultam no currículo real. Este sim, pode ser considerado reflexo da prática docente. As expectativas de ensino contempladas nos currículos oficiais não são as mesmas presentes nos currículos reais, pois a intervenção do docente e o contexto em que os discentes estão inseridos conferem singularidade ao currículo real, tornando-os distintos.

Para Silva (2015, p. 370), "[...] verifica-se, portanto, um distanciamento entre o que é produzido como discurso curricular oficial e o que é incorporado pelas escolas, haja vista que estas reinterpretam, reelaboram e redimensionam o que é proposto". Deve-se considerar que a carga horária da disciplina de química nas escolas públicas estaduais muitas vezes não é condizente com a excessiva demanda curricular. Tal cenário impõe um desafio diário aos docentes: formar alunos reflexivos, que articulem seus conhecimentos teóricos com sua realidade, mesmo com a falta de recursos, com o tempo limitado, com cobranças quantitativas para cumprir os conteúdos e outros problemas decorrentes do sistema de ensino e/ou da própria formação do docente.

\section{O Currículo Estadual de São Paulo}

No ano de 2008 a Secretaria de Educação lançou a Proposta Curricular para o Estado e, a partir de 2009, o Currículo passou a ser implantado nas escolas públicas estaduais. Ele tem como proposta a formação de um aluno que, por meio do desenvolvimento de competências e habilidades associadas ao conhecimento científico e sistemático, consiga intervir em sua sociedade de forma crítica e cidadã visando o bem comum. (SÃO PAULO, 2012).

Dentro do Currículo de Ciências da Natureza e suas Tecnologias, a disciplina de Química prevê a valorização do contexto e das experiências de vida, comuns aos alunos, para o desenvolvimento dos conhecimentos químicos. A ordem cronológica das descobertas científicas é respeitada e os conteúdos são apresentados de forma espiral, ou seja, são estudados em diferentes momentos do EM com níveis de aprofundamento distintos. A estrutura curricular da disciplina é organizada por série, por bimestre, por eixos temáticos (Ex: "Metais processos de obtenção", "Água e seu consumo pela sociedade" etc.) e por habilidades. (SÃO PAULO, 2012). 
[...] os conteúdos devem ser abordados de maneira que permitam o desenvolvimento de competências e habilidades relacionadas à comunicação e expressão, à compreensão e investigação e à contextualização e ação (PCN, 2002, p. 89-93) paralelamente ao desenvolvimento do pensamento formal. (SÃO PAULO, 2012, p. 128).

A comparação dos pressupostos desta estrutura curricular com a lista de conteúdos apresentados na Matriz de Referência do Enem (INEP, 2009) pode sinalizar a orientação para um ensino propedêutico voltado para a memorização, o que se opõe ao próprio discurso curricular: "[...] o ensino de Química deve se contrapor à simples memorização de informações, nomes, fórmulas e conhecimentos, que não guardam nenhum sentido com a realidade dos alunos" (SÃO PAULO, 2012, p. 125).

A consciência da possibilidade deste distanciamento ressalta a necessidade de haver consonância entre o currículo, a avaliação e a prática docente, ou seja, um efetivo diálogo entre os três campos.

Vários estudos chamam a atenção para o decisivo papel da prática docente e o necessário alinhamento entre as avaliações em larga escala e o currículo, tais como Webb (2007), Maceno et al. (2011) e Bonamino e Souza (2012). Dada a importância desta discussão, esta pesquisa busca compreender como a prática docente de um grupo de docentes é consolidada, com o olhar para a análise de conteúdos conceituais, buscando identificar a consonância entre essa prática, o Currículo Estadual Paulista de Química e o Enem.

\section{METODOLOGIA}

Este trabalho teve início com a análise documental (BARDIN, 1997; SÁ-SILVA et. al., 2009) das provas azuis do Enem aplicadas no período de 2009 a 2015. Após a identificação dos conhecimentos de química nos itens que compunham o exame, esses foram classificados de acordo com a subárea da química e os conteúdos conceituais (geral e específico). Posteriormente, os conteúdos conceituais elencados foram confrontados às orientações presentes no Currículo Estadual Paulista de Química (SÃO PAULO, 2012). Buscou-se identificar se estes conteúdos estavam presentes no currículo e em qual o momento $\left(1^{\circ}, 2^{\circ}\right.$ ou $3^{\circ}$ ano do EM) eles eram propostos.

Diante da extensa gama de conteúdos conceituais identificados nos 100 itens avaliados (provas dos anos de 2009 a 2015) foram escolhidos os conteúdos conceituais mais recorrentes para a construção de um instrumento de investigação, realizada por meio de um questionário.

O questionário elaborado é composto por duas partes: uma de caracterização do perfil dos docentes e outra contendo quatro perguntas fechadas utilizando escala Likert (HILL; HILL, 2009). Com esse questionário buscou-se identificar os conteúdos trabalhados pelo grupo de docentes. A utilização da escala Likert mostra-se adequada quando a finalidade é estimar uma variável latente (construto), que não pode ser medida diretamente, mas pode ser estimada pela associação de indicadores (BLAND; ALTMAN, 1997; CRONBACH, 1951). As questões presentes no questionário abarcaram a ocorrência e prioridade dos conteúdos na programação realizada pelo professor, a dificuldade e a receptividade relacionadas a esses conteúdos por parte dos alunos, na 
opinião dos professores. Esses questionamentos tinham como objetivo final obter indícios do currículo mínimo trabalhado por esse grupo de professores. $\mathrm{O}$ instrumento investigativo utilizado na pesquisa encontra-se no Apêndice A.

Foram analisadas as respostas de 24 professores da rede estadual da cidade de São Paulo e, devido à grande extensão da cidade, buscou-se a representação de docentes vinculados às distintas Secretarias de Educação do município para garantir variabilidade da amostra.

Os dados foram analisados após a codificação numérica dos mesmos, adotando as escalas listadas na Tabela 1:

Tabela 1 - Escalas de codificação numérica das respostas obtidas pelo questionário

\begin{tabular}{ccc}
\hline Questionamentos & 1) Ocorrência & $\begin{array}{c}\text { 2) Prioridade, 3) Dificuldade } \\
\text { e 4) Receptividade }\end{array}$ \\
\hline Não $=0$ & Não há $=0$ \\
$\begin{array}{c}\text { Escalas utilizadas }=1 \\
\text { na codificação das } \\
\text { respostas }\end{array}$ & $\begin{array}{c}\text { Não respondido } \\
=[\text { vazio }]\end{array}$ & Baixa $=1$ \\
& Intermediária $=2$ \\
& Não respondido $=3$
\end{tabular}

A partir dos dados brutos foram obtidas as ocorrências absolutas e relativas das respostas para cada uma das questões. Para identificar tendências nos resultados foram elaborados gráficos.

A correlação entre as variáveis analisadas foi estimada por meio do coeficiente alfa de Cronbach, que é uma estimativa de correlação entre as perguntas de um teste, e mede sua fiabilidade e assim, sugere sua confiabilidade. A confiabilidade pode ser compreendida como a intensidade da correlação, sendo esta um grau de consistência de medida de um conjunto de indicadores de determinada variável latente (BLAND; ALTMAN, 1997; CRONBACH, 1951). A estimativa do Alfa de Cronbach tem ampla aplicação no meio acadêmico e técnico como uma medida razoável da confiabilidade de um teste, por ter aplicação a questionários de múltipla escolha de escalas dicotômicas ou atitudinais de variáveis categóricas (como a escala Likert) e por ser facilmente calculável (OVIEDO; CAMPO-ARIAS, 2005).

\section{RESULTADOS}

A análise documental das edições do Enem de 2009 a 2015, que contemplaram 100 itens avaliando conceitos de química, possibilitou a classificação dos conteúdos conceituais de química, agrupando-os de acordo com as subáreas da Química: química orgânica, química geral e físico-química (ATKINS; JONES, 2012). A Figura 1 apresenta o número de itens em cada subárea nos anos avaliados. Química Geral foi a subárea que apresentou menor oscilação no número de itens no decorrer desses anos, se comparada à Química Orgânica e Físico-Química. 
Figura 1 - Representação da ocorrência dos conteúdos conceituais por subáreas da química em cada um dos anos avaliados. (FONTE: elaborada pelos autores).

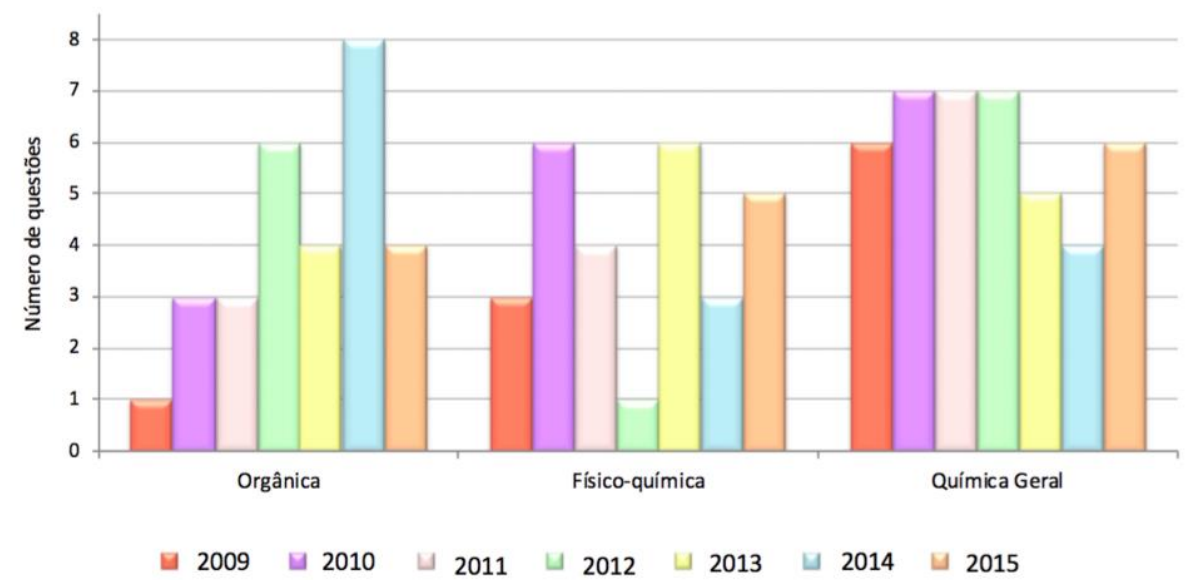

A Figura 1 ainda permite verificar que em determinados anos, a prova apresentou somente um item avaliando conhecimentos de uma subárea, como aconteceu com a química orgânica em 2009 e a físico-química em 2012. Na elaboração de um instrumento de avaliação deve-se levar em consideração vários aspectos, dentre eles, a consonância que deve existir entre a ocorrência e o balanço (quantidade de itens avaliando um determinado conhecimento) dos conteúdos nos exames e nos currículos ou documentos de orientação para elaboração dos testes (WEBB, 2007). A não observância desse aspecto pode comprometer a qualidade do instrumento de avaliação proposto ou privilegiar um determinado grupo de respondentes em detrimento de outros.

A verificação das ocorrências dos conteúdos conceituais, presentes nos itens, associadas ao ano em que o Currículo Estadual Paulista propõe o desenvolvimento do conteúdo é apresentada na Figura 2. A análise desse resultado precedeu a construção do questionário investigativo, uma vez que os conteúdos de maior recorrência foram selecionados para compor a listagem apresentada no instrumento de investigação (Apêndice A). 
Figura 2 - Ocorrência dos conteúdos conceituais (gerais e específicos) avaliados no Enem e presentes no Currículo Estadual Paulista. (FONTE: elaborada pelos autores).

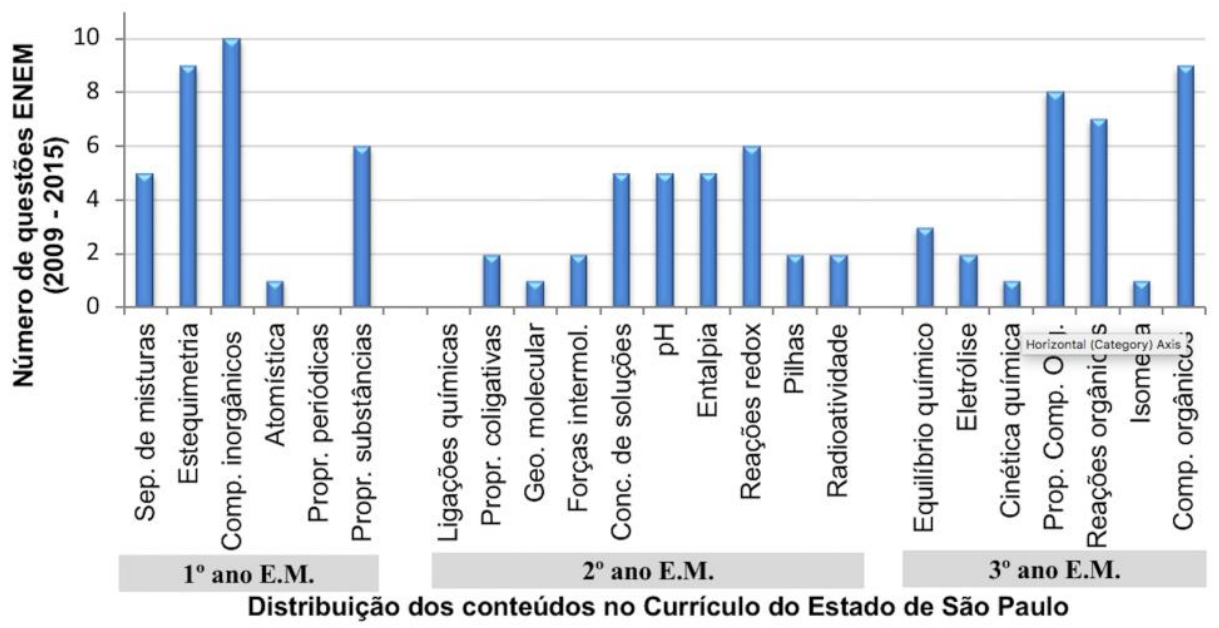

Na Figura 2 observa-se que alguns conteúdos específicos foram avaliados de forma sistemática nos sete anos analisados (estequiometria, compostos orgânicos e inorgânicos), enquanto que outros conteúdos presentes no Currículo Estadual Paulista (propriedades periódicas e ligações químicas, por exemplo) não estiveram presentes em nenhuma das provas analisadas. A explicação para esse fato pode estar associada à limitação imposta pelo espaço disponível na prova. A área de ciências da natureza, que inclui física, química e biologia, avalia seus conhecimentos em apenas 45 itens ou questões por prova, o que torna praticamente impossível avaliar todos os conteúdos presentes no currículo de ciências em uma única avaliação.

Conhecimentos associados à caracterização de substâncias inorgânicas, processos de separação de misturas e cálculos estequiométricos, propostos no Currículo Estadual Paulista para serem desenvolvidos no 10 ano do EM, estiveram em evidência nas provas do Enem estudadas. Por outro lado, apesar de atomística e propriedades periódicas serem conhecimentos bastante trabalhados nesta série, não foram avaliados em nenhuma das provas. Considerando que "[...] a estrutura atômica é um conhecimento chave para que todos os outros fenômenos químicos sejam compreendidos" (FERNANDES, 2015) e o conhecimento acerca da tabela periódica é base para a compreensão das propriedades dos materiais (TRASSI et al, 2001), pode-se pensar que esses podem ser considerados pré-requisitos a muitos dos conteúdos relacionados à transformação da matéria.

A recorrência de itens relacionados à eletroquímica (reações redox, pilhas e eletrólise) nas provas analisadas é algo a ser destacado. Esse cenário pode estar associado ao fato de eletroquímica ser conteúdo conceitual passível de contextualizações com o cotidiano dos alunos, condição sine qual non na elaboração de um item para compor a prova do Enem (INEP, 2010.). No Currículo Estadual Paulista eletroquímica é tratada com maior ênfase no 2o ano do EM, quando o aluno possui os conhecimentos prévios necessários (cátions, ânions, identificação do estado de oxidação das espécies, etc.) e apresenta maturidade acadêmica necessária para a compreensão de conceitos tipicamente abstratos 
associados a essa temática. Vale ressaltar que em um número considerável de escolas, os professores desenvolvem os conceitos de eletroquímica sem o apoio de aulas práticas em laboratórios ou simulações, que poderiam contribuir para minimizar as dificuldades relacionadas à aprendizagem desses conceitos.

Os conteúdos sugeridos no 3 o ano do Currículo Estadual Paulista mais contemplados nas provas estão relacionados à química do carbono (propriedades dos compostos orgânicos, reações orgânicas, funções orgânicas), indicando a importância desses conteúdos no exame. Nas orientações do Currículo Estadual Paulista os conteúdos para este nível escolar (equilíbrio químico, cinética química, química orgânica) são desenvolvidos de forma "suficiente para que o aluno construa uma visão abrangente da transformação química e entenda alguns processos químicos envolvidos na natureza e no sistema produtivo" (SÃO PAULO, 2012, p. 129).

\section{Investigação acerca dos conceitos de química presentes nas aulas de um grupo de professores}

Os resultados apresentados a seguir são provenientes dos questionários respondidos por 24 docentes de escolas públicas estaduais da cidade de São Paulo. O grupo é representado por professores com idade acima de 36 anos, todos licenciados e, prioritariamente, com graduação em química ou engenharia química. A maioria atua na rede estadual por mais de 9 anos e está vinculada de forma efetiva à mesma escola há no mínimo 3 anos, ministrando para as três séries do EM. Praticamente a metade do grupo possui pós-graduação e/ou cursos de extensão. Além de atuar na rede estadual, a maioria dos docentes atua ou já atuou também na rede de ensino particular. Na Figura 3 são apresentadas algumas características dos docentes participantes.

Figura 3 - Sequência de resultados relacionados ao perfil docente, sendo: a) sexo, b) área de formação, c) séries de atuação e d) tempo de atuação na rede pública estadual de ensino. (FONTE: elaborada pelos autores).

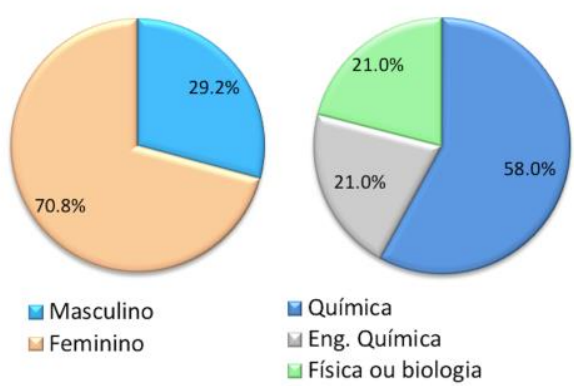

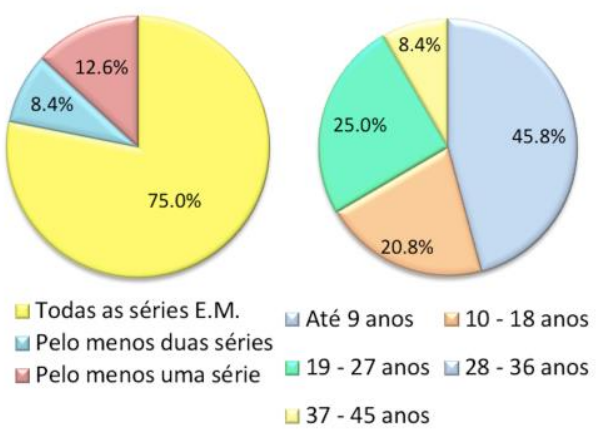

$\sqcup 37-45$ anos

Os docentes participantes do projeto classificaram os 22 conteúdos conceituais, presentes no Currículo Estadual Paulista e nas provas do Enem avaliadas neste estudo, de acordo com as quatro perguntas com escala Likert (VIEIRA, 2009), considerando: a ocorrência dos conteúdos no planejamento de aula, a prioridade dos conteúdos para o desenvolvimento acadêmico dos alunos, 
a dificuldade e a receptividade dos alunos frente aos conteúdos apresentados (Apêndice A).

Tomando cada conteúdo conceitual como uma variável, analisada sob o ponto de vista dos quatro questionamentos, determinou-se o alfa de Cronbach para cada um deles a fim de estimar a confiabilidade. A média aritmética encontrada para os alfas de Cronbach foi 0,77 que, segundo Vieira (2009), está dentro de um valor substancial/aceitável de consistência. Considerou-se também a média aritmética para os conteúdos separados por série, tal que: os alfas do 1응 e do 2 o ano do EM são 0,77 e do 3 o ano é 0,76 , que também estão na faixa aceitável de confiabilidade.

Na Figura 4 são apresentadas as porcentagens das respostas dadas pelos docentes aos questionamentos. Os resultados foram convertidos em percentagem considerando como padrão o valor máximo que os 24 respondentes poderiam atribuir para cada resposta. Questionamento 1 (Desenvolvimento ou não do conteúdo na sala de aula): para os conteúdos assinalados pelos docentes computou-se o valor 1, para conteúdos não assinalados considerou-se valor 0 . Neste caso, a porcentagem correspondente a $100 \%$ indica que todos os docentes assinalaram o conteúdo. Questionamento 2 (Prioridade do conteúdo no desenvolvimento acadêmico): neste caso as repostas foram atribuídas de acordo com a escala Likert de 0 a 3, sendo 0 para "não é prioridade" e valor 3 para "prioridade alta". As porcentagens foram obtidas considerando como $100 \%$ os valores máximos permitidos. Os dados dos questionamentos 3 e 4 foram analisados de acordo com o critério para o questionamento 2. A Figura 4 ainda lista a ocorrência de cada conteúdo conceitual nos anos avaliados do exame.

Figura 4 - Percentagens obtidas a partir dos dados dos questionários respondidos pelos docentes e ocorrência dos conteúdos conceituais no Enem por ano de aplicação.

\begin{tabular}{|c|c|c|c|c|c|c|c|c|c|c|c|c|c|}
\hline & \multirow[b]{3}{*}{ Conteúdos } & \multirow{2}{*}{\multicolumn{4}{|c|}{ Variáveis em percentagem (\%) }} & & & & & & & & \\
\hline & & & & & & \multicolumn{8}{|c|}{ Ocorrência nas provas do ENEM } \\
\hline & & Ocorrência & Prioridade & Dificuldade & Receptividade & 2009 & 2010 & 2011 & 2012 & 2013 & 2014 & 2015 & Total \\
\hline \multirow{6}{*}{$\begin{array}{l}\text { 12. ano } \\
\text { E.M. }\end{array}$} & Separação de misturas & 100,0 & 82,6 & 26,1 & 85,5 & & 1 & 1 & & 1 & 1 & 1 & 5 \\
\hline & Cálculo estequiométrico & 91,3 & 90,9 & 84,8 & 40,9 & & 3 & 3 & 1 & 1 & & 1 & 9 \\
\hline & Compostos inorgânicos & 100,0 & 84,8 & 42,9 & 66,7 & 1 & 2 & 1 & 2 & 1 & 2 & 1 & 10 \\
\hline & Atomistica & 100,0 & 89,9 & 33,3 & 69,6 & 1 & & & & & & & 1 \\
\hline & Propriedades periódicas & 95,2 & 73.9 & 53,0 & 56,5 & & & 1 & 1 & & & & 2 \\
\hline & Propriedades das substâncias & 100,0 & 90,3 & 37,5 & 77,8 & 1 & & 1 & 2 & & 1 & 1 & 6 \\
\hline \multirow{10}{*}{$\begin{array}{l}2^{2} \text { ano } \\
\text { E.M. }\end{array}$} & Ligações químicas & 100,0 & 94,2 & 59,8 & 65,3 & & & & & & & & 0 \\
\hline & Propriedades coligativas & 54,5 & 63,6 & 73,7 & 40,0 & & & 1 & 1 & & & & 2 \\
\hline & Geometria molecular & 77,3 & 65,0 & 79,4 & 40,9 & & & & & & 1 & & 1 \\
\hline & Forças intermoleculares & 90,9 & 87,9 & 74,2 & 46,9 & & & 1 & & 1 & & & 2 \\
\hline & $\mathrm{pH}$ & 90,9 & 85,5 & 57,9 & 72,5 & 1 & 1 & & 1 & 1 & 1 & & 5 \\
\hline & Entalpia & 68,2 & 69,7 & 66,7 & 51,7 & 1 & 2 & 1 & & & & 1 & 5 \\
\hline & Eletrólise & 72,7 & 68,2 & 81,7 & 42,9 & & 1 & & & 1 & & & 2 \\
\hline & Reações redox & 81,8 & 76,8 & 75,8 & 50,0 & 1 & & & 1 & & 2 & 2 & 6 \\
\hline & Pilhas & 95,5 & 78,3 & 75,8 & 50,7 & & 1 & & & 1 & & & 2 \\
\hline & Radioatividade & 54,5 & 61,1 & 66,7 & 63,5 & & & & & 1 & & 1 & 2 \\
\hline \multirow{6}{*}{$\begin{array}{c}\text { 32 ano } \\
\text { E.M. }\end{array}$} & Equilibrio químico & 85,0 & 78,3 & 81,2 & 48,5 & & 1 & 1 & & & & 1 & 3 \\
\hline & Cinética química & 100,0 & 81,8 & 63,5 & 61,9 & 1 & & & & & & & 1 \\
\hline & $\begin{array}{l}\text { Propriedades de compostos } \\
\text { orgânicos }\end{array}$ & 100,0 & 85,5 & 57,6 & 57,6 & & & 1 & 3 & 1 & 2 & 1 & 8 \\
\hline & Reações orgânicas & 80,0 & 71,0 & 88,8 & 31,7 & & 1 & 1 & 2 & 2 & & 1 & 7 \\
\hline & $\begin{array}{l}\text { Isomeria de compostos } \\
\text { orgânicos }\end{array}$ & 70,0 & 65,2 & 68,3 & 47,6 & & & & & 1 & & & 1 \\
\hline & $\begin{array}{l}\text { Compostos orgânicos } \\
\text { (funçổes, nomenclatura) }\end{array}$ & 100,0 & 89,4 & 46,0 & 66,7 & 1 & 1 & & 2 & 1 & 2 & 2 & 9 \\
\hline
\end{tabular}


Ocorrência, prioridade e receptividade Dificuldade \begin{tabular}{|l|l|l|l|}
\hline Muito baixa: $0-24,0 \%$ & Baixa: $25,0-49,0 \%$ & Intermediaria: $50,0-74,0 \%$ & Alta: $75,0-100,0 \%$ \\
\hline Muito baixa: $0-24,0 \%$ & Baixa: $25,0-49,0 \%$ & Intermediaria: $50,0-74,0 \%$ & Alta: $75,0-100,0 \%$
\end{tabular}

(Fonte: elaborada pelos autores).

De acordo com os resultados apresentados na Figura 4, os conteúdos desenvolvidos no 1 o ano do EM aparentam ser mais recorrente nas aulas, uma vez que os professores os consideram prioritários, os alunos apresentam muito baixa ou baixa dificuldade para a sua compreensão e possuem receptividade alta ou intermediária (cálculo estequiométrico é exceção a esse cenário). Cálculo estequiométrico diverge, pois embora tenha classificação de alta ocorrência e prioridade, a dificuldade para o aprendizado é alta, possivelmente devido aos problemas enfrentados pelos os alunos que necessitam utilizar conhecimentos de outra área do conhecimento (matemática). Analisando os conteúdos avaliados nas provas do Enem observa-se que aqueles correspondentes a essa série são, também, bastante recorrentes. Esse sincronismo é interessante, pois num processo avaliativo em larga escala deve haver consonância entre o que é avaliado nos testes, as orientações presentes nos currículos e o que é ensinado nas salas de aulas (WEBB, 2007). Ressaltamos que os resultados apresentados neste trabalho não fornecem garantias de que esses conteúdos conceituais estão sendo efetivamente desenvolvidos nas aulas ministradas pelos professores que participaram da pesquisa, pois não estivemos presentes nas aulas ministradas por eles para verificar efetivamente essas ocorrências. Entretanto, consideramos que os dados provenientes das respostas dos docentes permitem traçar um cenário com base em seus relatos, suas percepções e experiências.

Nem todos os conteúdos listados no 20 ano do EM estiveram presentes nos planejamentos das aulas analisadas dos docentes. Conteúdos como propriedades coligativas e radioatividade foram identificados em cerca de somente $50 \%$ das respostas. Esse resultado pode ser explicado pelo fato destes conteúdos não serem contemplados no conteúdo programático da disciplina Química, sugerida no Currículo Oficial, entretanto vêm sendo avaliados no Enem. Chama a atenção a ocorrência intermediária da temática entalpia, uma vez que transformações químicas envolvendo diferentes combustíveis e suas variações de energia é uma temática bastante recorrente no material didático oferecido pelo governo estadual paulista (CISZEVSKY, 2016). Nas provas analisadas o conceito de entalpia esteve presente quatro vezes no conjunto das sete provas analisadas.

No processo de aprendizagem, todos os conceitos indicados no $2^{\circ} \mathrm{EM}$ foram considerados de dificuldade intermediária ou alta. Eletrólise, reações redox e pilhas foram aqueles considerados mais difíceis. Ainda, de acordo com os docentes, os alunos apresentam baixa receptividade na aprendizagem de todos esses conteúdos, com exceção de $\mathrm{pH}$, que apresenta receptividade intermediária. A explicação para esse cenário pode estar relacionada aos conhecimentos prévios necessários para a aprendizagem desses conteúdos e às dificuldades intrínsecas a conceitos muitas vezes abstratos, ou que utilizam uma linguagem além da textual, como a gráfica e a algébrica, bastante comuns na físico-química. (ATKINS; DE PAULA, 2008).

Dos 28 itens nos quais conhecimentos relacionados à físico-química foram necessários para a resolução da situação-problema, 10 itens avaliaram conhecimentos relacionados à eletroquímica (reações redox, pilhas e eletrólise). Diante deste cenário, pode-se inferir que nos conteúdos relacionados ao $2^{\circ}$ ano 
do EM há certo distanciamento entre os prováveis conteúdos trabalhados pelo grupo de docentes e os conhecimentos avaliados nos exames do Enem nos anos analisados.

De acordo com o Currículo Estadual Paulista, no 3o ano do EM há previsão do estudo de alguns conceitos relacionados com a físico-química (equilíbrio químico e cinética) e química orgânica. A maioria dos docentes informou em suas respostas que considera que esses conteúdos fazem parte das ementas de seus cursos e que eles são prioritários no desenvolvimento acadêmico do estudante. Ainda, de acordo as repostas, os estudantes apresentam dificuldade alta ou intermediária no estudo destes conceitos e não apresentam alta receptividade. Uma maior receptividade é observada para o ensino de funções e nomenclaturas orgânicas, de acordo com as respostas de $66,7 \%$ dos docentes. Um fato que chama a atenção é que em 24 dos 29 itens, presentes no Enem e com conteúdos conceituais aprendidos no 3 을 ano do EM, foram avaliados conceitos relacionados à química orgânica.

Na busca pelo currículo real, ou seja, aquele que efetivamente ocorre na sala aula, deve-se também levar em consideração um ceário que envolve dificuldades institucionais e/ou pessoais e que não podem ser conhecidas somente pela verificação da ocorrência dos conteúdos nas esferas de avaliações, currículo e instrução. Sabe-se que para se atingir o alinhamento necessário entre essas dimensões deve levar em consideração a realidade de cada escola, o perfil dos alunos, o tempo disponível para cada disciplina, o currículo, a formação e desenvolvimento profissional dos docentes, entre outros.

Os resultados apresentados na Figura 4 suportam a hipótese de que há consonância efetiva apenas para os conteúdos orientados para o 1ํ ano do EM, pois os indicadores (ocorrência, prioridade, dificuldade e receptividade) se relacionam com equivalência para a maioria dos conteúdos, exceto cálculo estequiométrico devido implicações externas à disciplina de química (o extenso uso de ferramentas provenientes da matemática). Esta análise não tem como pretensão sugerir que as avaliações externas sejam o norte para o Currículo ou para o ensino em sala de aula, como criticam Bonamino e Souza (2012), mas que haja um alinhamento dos conteúdos avaliados nas provas aplicadas com o que é exigido dos alunos no período de escolarização.

Outro ponto de deve ser levado em consideração é que a consonância na ocorrência dos conteúdos nos objetivos educacionais e nas provas é um dos requisitos mínimos necessários. Aspectos relacionados ao nível de complexidade com que o conhecimento é avaliado e o balanço de representação, que prevê como os conhecimentos avaliados nos itens estão distribuídos em concordância com os objetivos educacionais previstos para aquele nível de ensino em que respondente se encontra (MARTONE; SIRECI, 2009), também devem ser observados.

\section{CONCLUSÃO}

De acordo com os critérios aplicados neste estudo, o alinhamento entre os conteúdos conceituais presentes no currículo, na prática de um grupo de docentes e nas provas do Enem foi observado apenas para os conteúdos previstos para o 1ㅇan ano do EM nas escolas públicas estaduais. Parte dos conceitos 
associados a esses conteúdos possui caráter menos abstrato e menor demanda de conhecimentos prévios, apresentando menor grau de dificuldade para sua compreensão.

Quanto aos conteúdos conceituais orientados ao 2을 ano do EM, foi observado um distanciamento entre o cenário associado à prática docente do grupo de professores e as provas aplicadas do Enem. A falta de diálogo pode ser exemplificada quando se observa que nas sete edições do Enem analisadas conteúdos de eletroquímica estiveram presentes. Sabe-se que o desenvolvimento destes conteúdos implica em um considerável conhecimento prévio de conceitos e, devido ao seu caráter abstrato, os alunos apresentam dificuldade para compreende-los demandando, consequentemente, um trabalho mais árduo do docente, que pode optar por uma abordagem mais superficial. Nos resultados apresentados para o $3^{\circ}$ ano do EM, a química orgânica também contribuiu para esse distanciamento.

Os resultados apontam que, embora os docentes entrevistados tenham elencados a maioria dos conceitos em seus planejamentos e os considerados prioritários, eles também demonstram terem percepção de que os alunos possuem alta dificuldade e baixa receptividade no estudo de parte desses conteúdos. Nesta reflexão não pode ser desconsiderado o cenário das escolas públicas estaduais paulistas: insuficiente número de aulas semanais de química; deficiências nas dependências físicas das escolas que, na maioria das vezes não possui laboratórios didáticos e ambientes adequados para o ensino de ciências; elevado número de alunos nas salas, comprometendo seriamente do trabalho do docente; e ainda ser composta por um número significativo de grupos sociais menos favorecidos (VALENTE, 2016).

Considerando a trajetória de ensino proporcionada para os estudantes das escolas públicas estaduais, a exigência para a resolução dos itens de química do Enem costuma ser alta. Assim, faz-se necessária a reflexão sobre a necessidade de criar um diálogo efetivo entre o currículo, a prática docente e o Enem que viabilize o alinhamento entre o currículo real e os conhecimentos avaliados no maior exame de seleção do País, com vistas a proporcionar uma seleção equitativa para o ensino superior. 


\title{
Reflections based on dialogue among chemistry's items on exame nacional do ensino médio (ENEM), on curriculum and in teaching pratice
}

\begin{abstract}
The aims of this work are to propose a dialogue between three important elements in basic education: the curriculum, the teaching practice and external evaluations, especially the Enem. The conceptual contents investigated were selected based on the analysis of items present in the blue tests of Enem, applied from 2009 to 2015, and the Curriculum of State of São Paulo. These contents selected were investigated in a questionnaire with Likert scale. The questionnaire was answered by a group of chemistry teachers that working in state public schools. Teachers analyzed the contents accordingly four criteria: occurrence in classroom, priority for the teacher, difficulty and receptivity for the students. The results show congruence between the elements analyzed for contents oriented to the 1st year of high school, characterized by knowledge of general chemistry. For the 2nd and 3rd years of high school, there was a divergence between contents evaluated in the tests of those present in the real curriculum, developed by the teachers.
\end{abstract}

KEYWORDS: Enem. Curriculum. Teaching practice. Chemistry teaching. 


\section{REFERÊNCIAS}

ATKINS, P. W..; JONES, L. Princípios de Química: Questionando a Vida Moderna e o Meio Ambiente. 5. ed. Porto Alegre: Bookman, 2012. 922p.

PAULA, J. Físico-Química. 9. ed. Rio de Janeiro: LTC, 2012. 386p.

BARDIN, L. Análise de conteúdo. Lisboa: Edições, 1997. p. 45-46.

BLAND, J. M.; ALTMAN, D. G. Statistics notes: Cronbach's alpha. BMJ, v. 314, n. 7080, 572p, 1997.

BONAMINO, A.; SOUSA, S. Z. Três gerações de avaliação da educação básica no Brasil: interfaces com o currículo da/na escola. Educação e Pesquisa, São Paulo, v.38, n.2, p.373-388, abr./jun. de 2012.

BRASIL. Edital N ${ }^{\circ} 13$, de 7 de Abril de 2017. Exame Nacional Do Ensino Médio Enem 2017. Diário Oficial União, Brasília, DF, № 69, 10 de abril de 2017. Seção 3, p.47.

CISZEVSKY, E. O. S. Reflexões sobre o ensino de Química baseadas no diálogo entre o ENEM e o Currículo Estadual Paulista. 2016. Dissertação de Mestrado. Programa de Pós-Graduação Stricto Sensu de Mestrado Profissional em Ensino de Ciências e Matemática. Instituto Federal de Educação, Ciência e Tecnologia de São Paulo - IFSP, São Paulo.

CRONBACH, Lee J. Coefficient alpha and the internal structure of tests. Psychometrika, v. 16, n. 3, p. 297-334, 1951.

DE BLASIS, E. Avaliações em larga escala: contribuições para a melhoria na qualidade da educação. Cadernos Cenpec/Nova Série, v. 3. n. 1., p. 251-268, jun. 2013.

INEP. Matriz de Referência para o ENEM 2009. Brasília, 2009.

Guia de elaboração e revisão de itens. Brasília, 2010.

FACHINETTO, S. M. K. Estudo comparativo entre o público EJA e o público regular utilizando a análise do funcionamento diferencial do item (DIF), na área de Ciências da Natureza e suas Tecnologias, a partir dos dados do ENEM 2012. 
Pós-Graduação em Métodos e Gestão em Avaliação. Universidade Federal de Santa Catarina, Centro Tecnológico. Florianópolis.

FERNANDES, M. Aplicação do jogo Ludo Atomística no Ensino de Química. Universidade Federal de São Carlos. Dissertação de Mestrado. 2015. 192p. Programa de Pós-Graduação em Química (Mestrado Profissional). Universidade Federal de São Carlos. São Carlos.

HILL, M. M., HILL, A. Investigação por Questionário. 2. ed., Lisboa: Edições Sílabo. 2002. 378p.

MACENO, N. G. et al. A matriz de referência do Enem 2009 e o desafio de recriar o currículo de química na educação básica. Química Nova na Escola, v. 33, n. 3, p. 153-159, 2011.

MARCELINO, L. V., RECENA, M. C. P. Possíveis influências no Novo ENEM nos currículos educacionais de Química. Estudos em Avaliação Educacional, São Paulo, v. 23, n. 53, p. 148 - 177. set/dez, 2012.

MARTONE, A; SIRECl, S. G. Evaluating Alignment Between Curriculum, Assessment and Instruction. Review of Education Research, v. 79, n. 4, p. 1332 1361, dez. 2009.

OVIEDO, H. C. CAMPO-ARIAS, A. Aproximación al uso del coeficiente alfa de Cronbach. Revista Colombiana de Psiquiatría, vol. XXXIV, núm. 4, p. $572-580$. 2005. Disponível em: <http://www.redalyc.org/pdf/806/80634409.pdf>. Acesso em: 21 set. 2017.

SÁ-SILVA, J. R.; DE ALMEIDA, C. D.; GUINDANI, J. F. Pesquisa documental: pistas teóricas e metodológicas. Revista Brasileira de História \& Ciências Sociais, v. 1, n. 1, 2009.

SACRISTÁN, J. G. O currículo: uma reflexão sobre a prática. Porto Alegre: Artmed, 2000, p.119-148.

SÃO PAULO (Estado). Secretaria da Educação. Currículo do Estado de São Paulo: Ciências da Natureza e suas Tecnologias. São Paulo, 2012. Disponível em: <http://www.educacao.sp.gov.br/curriculo>. Acesso em: 15 out. 2016.

SHEPARD, L. A.; PENUEL, W. R.; DAVIDSON, K. L. Design Principles for New Systems of Assessment. Phi Delta Kappan, v.98 n.6. 47-52p, 2017. 
SILVA, M. R. Currículo, ensino médio e BNCC - Um cenário de disputas. Revista Retratos da Escola, Brasília, v. 9, n. 17, p.367-379, jul./dez. 2015. Disponível em: $<$ http//www.esforce.org.br>.

TRASSI, R. C. M.; CASTELLANI, A. M.; GONÇALVES M. J. E.; TOLEDO, E. A. Tabela periódica interativa: "um estímulo à compreensão". Acta Scientiarum, v. 23, n. 6, p. 1335 - 1339; Maringá, 2001. Disponível em: <http://ojs.uem.br/ojs/index.php/ActaSciTechnol/article/view/2757/1824>. Acesso em: 24 ago. 2017.

VALENTE, R. R. The vicious circle: effects of race and class on university entrance in Brazil. Race Ethnicity And Education. v. 20, n.6, p. 851-864, 2017.

VALVERDE, G. A. Padrões e Avaliação. In: SCHWARTZMAN, S.; COX, C. (Org.) CHRISTOPHE, M.; CALDAS R. (tradução). Políticas educacionais e coesão social: uma agenda latino-americana. Rio de Janeiro: Elsevier, 2010.

VIEIRA, S. Como elaborar questionários. São Paulo: Editora Atlas SA, 2009.

WEBB, N. L. Issues related to judging the alignment of curriculum standards and assessments. Applied Measurement in Education, Philadelphia, v. 20, n. 1, p. 725, 2007. 
APÊNDICE A - Instrumento de investigação: questionário

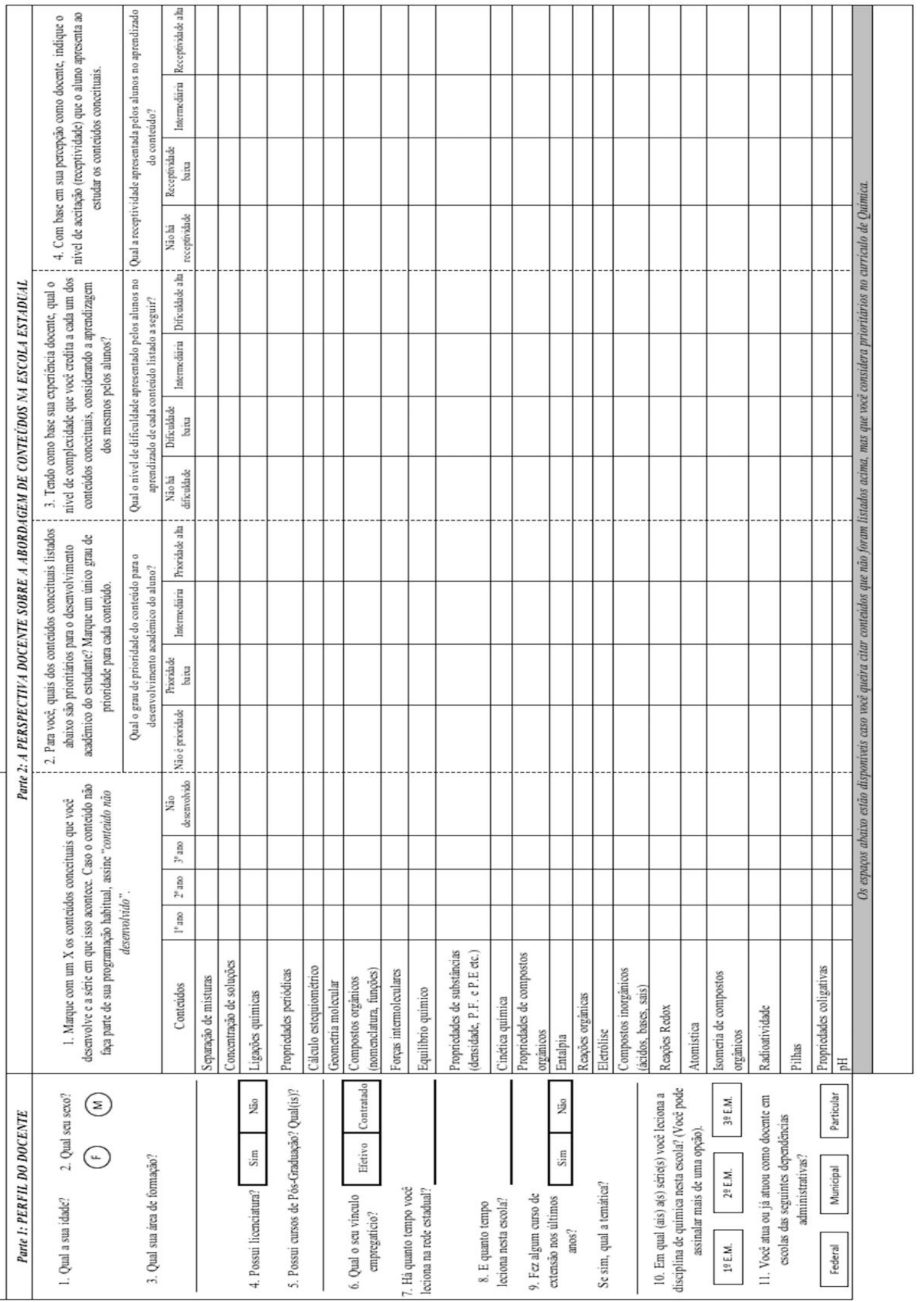

Página | 306 
Recebido: 2018-04-22

Aprovado: 2018-04-22

DOI: $10.3895 /$ rbect.v12n2.8179

Como citar: CARVALHO, L. T.; CISZEVSKI, E. S.; CINTRA, E. P. Reflexões baseadas no diálogo entre o exame nacional do ensino médio, currículo e prática docente no ensino de química. Revista Brasileira de Ensino de Ciência e Tecnologia, v. 12, n. 2, 2019.

Disponível em: <https://periodicos.utfpr.edu.br/rbect/article/view/8179>. Acesso em: $\mathrm{xxx}$.

Correspondência: Elaine Pavini Cintra - elainecintra@ifsp.edu.br

Direito autoral: Este artigo está licenciado sob os termos da Licença Creative Commons-Atribuição 4.0 Internacional.

(c) 